\title{
Osteogenic Predifferentiation of Human Bone Marrow-Derived Stem Cells by Short-Term Mechanical Stimulation
}

\author{
Doerte Matziolis ${ }^{*}, 1$ Jens Tuischer ${ }^{1}$, Georg Matziolis ${ }^{1}$, Grit Kasper ${ }^{2}$, Georg Duda ${ }^{2}$ and Carsten Perka ${ }^{1}$ \\ ${ }^{\text {I} O r t h o p a e d i c ~ D e p a r t m e n t, ~ C e n t e r ~ f o r ~ M u s c u l o s k e l e t a l ~ S u r g e r y, ~}{ }^{2} J u l i u s$ Wolff Institute, Charité, University Medicine \\ Berlin, Germany
}

\begin{abstract}
It is commonly accepted that bone marrow-derived stem cells (BMSCs) have to be expanded in vitro, but a prolonged time in culture decreases their multilineage potential. Mechanical and biological stimuli have been used to improve their osteogenic potential. While long-term stimulation has been shown to improve osteogenic differentiation, it remains to be seen whether short-term stimulation is also sufficient.

We investigated the influence of 24 hours' cyclic loading $(0.05 \mathrm{~Hz}, 4 \mathrm{kPa})$ on gene expression of human BMSCs in threedimensional fibrin-DMEM constructs $(n=7)$ in a compression bioreactor using DNA-array technology. Expression of the following genes showed a significant increase after mechanical stimulation: 2.6 -fold osteopontin (OPN) and integrin- $\beta 1$ (ITGB1), 2.2-fold transforming growth factor- $\beta$-receptor 1 (TGF- $\beta$-R1) and 2.4-fold SMAD5 expression, compared to controls without mechanical stimulation ( $\mathrm{p}<0.05$ each). Platelet-derived growth factor- $\alpha$ (PDGF- $\alpha)$ and annexin-V were also significantly overexpressed, the mechanical stimulation resulting in a 1.8-fold and 1.6-fold expression $(\mathrm{p}<0.05)$.

Cells were identified as osteoblast precursors with a high proliferative capacity. Given the identical in-vitro environment for both groups, the increase in gene expression has been interpreted as a direct influence of cyclic mechanical stimulation on osteogenic differentiation. It may be postulated that short-term mechanical stimulation results in an improved osseous integration of tissue engineered grafts in bone defect healing.
\end{abstract}

Keywords: Osteogenic predifferentiation, human bone marrow-derived stem cells, mechanical stimulation, bioreactor.

\section{INTRODUCTION}

Major bone defects remain an unsolved therapeutic problem in orthopaedic surgery, especially in revision arthroplasty, treatment of pseudarthrosis or after tumour resections [1]. The use of autologous and allogenic bone grafts is the most widely used regenerative approach [2]. Fundamental differences in biology have been noted in these two approaches: Allografts demonstrate only osteoconductive capacity with low overall integration and an unsatisfactory long-term clinical outcome [3-5]. Autografts show osteoinductive and osteogenic characteristics, leading to significantly better clinical results [6]. However, their use is limited by restricted availability and significant donor-site morbidity [7].

A therapeutic approach that harnesses the osteogenic potential of autografts, without the limitations of low availability and high donor-site morbidity is still missing in the treatment of bone defects.

Therefore, autologous osteogenic cells like periosteumderived cells in different matrices have been investigated in regenerative bone defect therapy and promising results have been published $[8,9]$. Bone marrow-derived stromal cells have also been investigated in animal and clinical trials, an accelerated healing of bone defects being reported [10-13].

*Address correspondence to this author at the Orthopaedic Department, Center for Musculoskeletal Surgery, Charité - University Medicine Berlin, Charitéplatz 1, D-10117 Berlin, Germany; Tel: 0049 - 30 - 450652206; Fax: 0049 - 30 - 450515909; E-mail: doerte.matziolis@charite.de
BMSCs have little donor-site morbidity and are easily expanded in vitro [14], but their multilineage potential and proliferative capacity decreases with time in vitro [15]. It has therefore been recommended to keep the in-vitro phase as short as possible in clinical situations $[16,17]$. A predifferentiation of cells during the in-vitro period has been reported to be beneficial, as the osteogenic potential of BMSCs can be augmented through biological or mechanical stimulation lasting for several weeks $[18,19]$.

In the present study we wanted to investigate whether a short-term mechanical stimulation of just 24 hours is sufficient to achieve an osteogenic predifferentiation in vitro. A short period of stimulation and thereby short in-vitro time might be advantageous for subsequent in-vivo use. Maintaining the high proliferative capacity and directing the cellular differentiation into an osteogenic lineage may improve results of cell-based approaches in the treatment of bone defects.

\section{MATERIALS AND METHODOLOGY}

\section{Study Design}

BMSCs were harvested from seven different donors, all cells then being expanded separately in cell-culture flasks. After a sufficient amount of cells had been achieved, they were transferred into three-dimensional constructs consisting of an elastic fibrin-DMEM matrix and then put between two slices of freeze-dried cancellous bone. All constructs were placed in bioreactors, as described previously [20]. Half of the constructs underwent cyclic mechanical compression; the other half remained without mechanical stimulation as a 
control. The gene expression in mechanically stimulated cells was normalized versus unstimulated controls.

\section{Cells and Cell Culture}

The BMSCs were gained from aspirates of the proximal femur during total hip arthroplasty operations. All 7 donors (4 female, 3 male, average age 61 years) gave informed consent. A pre-existing bone disease was excluded anamnestically and by bone densitometry investigation (Lunar-DPX, USA). Approximately $5 \mathrm{ml}$ bone-marrow aspirate were harvested from the intertrochanteric region of the proximal femur, and kept at $8^{\circ} \mathrm{C}$ until further processing within 4 hours.

Density centrifugation was performed (Histopaque $1.077 \mathrm{~g}$ - Sigma-Aldrich, Germany) for 15 minutes at $1500 \mathrm{rpm}$. The interphase containing the BMSCs was transferred into culture medium (DMEM $+10 \%$ FCS [Biochrome, Germany] $+100 \mathrm{U} / \mathrm{ml}$ penicillin $+100 \mu \mathrm{g} / \mathrm{ml}$ streptomycin [Sigma-Aldrich, Germany]). The cells were dispersed in culture flasks (Falcon, Greiner, Germany) and then incubated at $37^{\circ} \mathrm{C}$ and $5 \% \mathrm{CO}_{2}$. Passage into a new flask was performed at approximately $70 \%$ confluence.

\section{D Matrix/Bone-Fibrin-DMEM Constructs}

After having reached passage 3 in the above given cell culture medium, cells were transferred into $3 \mathrm{D}$ constructs, consisting of a fibrin-DMEM-mix matrix and placed between two slices of freeze-dried human cancellous bone. Every construct contained $1 \times 10^{6}$ cells in $600 \mu 1$ DMEM + $10 \% \mathrm{FCS}$ (Biochrome, Germany) $+100 \mathrm{U} / \mathrm{ml}$ penicillin + $100 \mu \mathrm{g} / \mathrm{ml}$ streptomycin (Sigma-Aldrich, Germany) $+2.4 \%$ aprotinin (Bayer, Germany). For polymerization 30 $\mu 1$ fibrinogen and $1 \mathrm{IU} / \mathrm{ml}$ thrombin (Aventis, Germany) were added. The matrices hardened for one hour at $37^{\circ} \mathrm{C}$ at $5 \%$ $\mathrm{CO}_{2}$, before being transferred into the bioreactors.

The freeze-dried cancellous bone slices measured $15 \mathrm{~mm}$ in diameter and $4 \mathrm{~mm}$ in depth. Prior to construct mounting, they were rehydrated for two hours in culture medium.

\section{Mechanical Stimulation in the Compression Bioreactor}

The principle of the compression bioreactor (Fig. 1) has been described previously [20]. A closed cylindrical polyethylene chamber communicates with the incubator via four sterile filters $(0.2 \mu \mathrm{m}$ pore diameter). The cell-matrix constructs were mechanically stimulated between two flexible silicon membranes. While the upper membrane loads the construct (Fig. 2) perpendicularly to its surface, the lower membrane transfers the pressure via a standard infusion tube to a pressure transducer.

In the present experiment, we applied a cyclical pressure of $4 \mathrm{kPa}$, resulting in a deformation of approximately $1 \mathrm{~mm}$ $(\Delta \mathrm{h} / \mathrm{h}=25 \%)$, at a frequency of $0.05 \mathrm{~Hz}$. The loading environment of the lower extremities during physiological activities such as walking and running is cyclic [21], and the frequency used in our experiment has been described to be within physiological conditions [22]. Control constructs $(n=7)$ were cultivated in bioreactors without mechanical stimulation. After 24 hours, the cyclic compression was terminated and the constructs were harvested.

\section{RNA Extraction and Gene Expression}

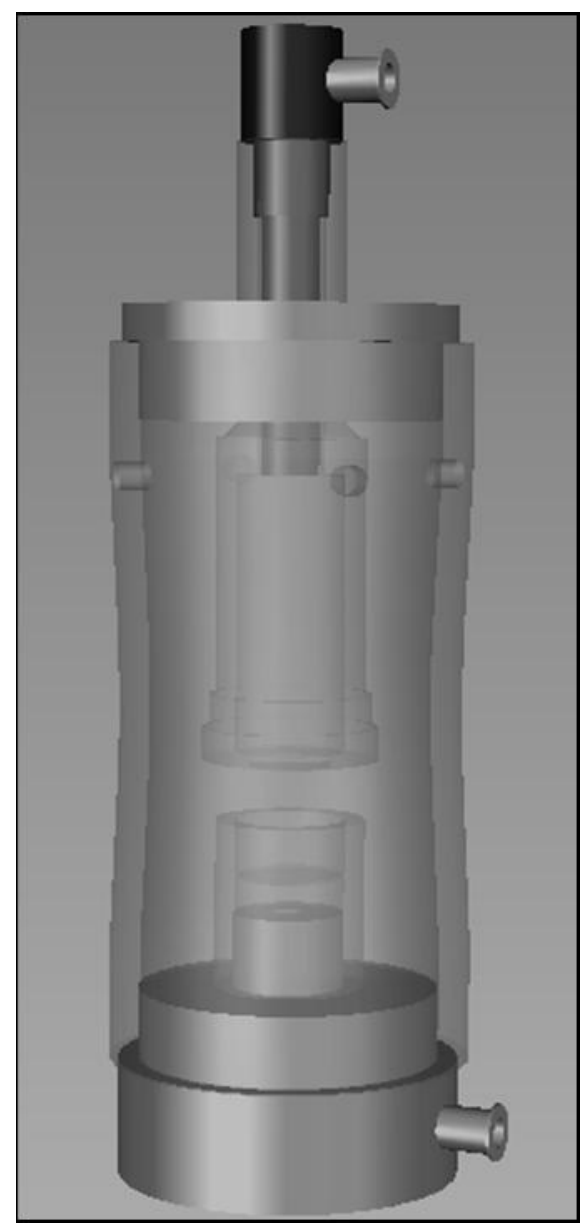

Fig. (1). Compression bioreactor for cyclic loading of the constructs under sterile culture conditions.

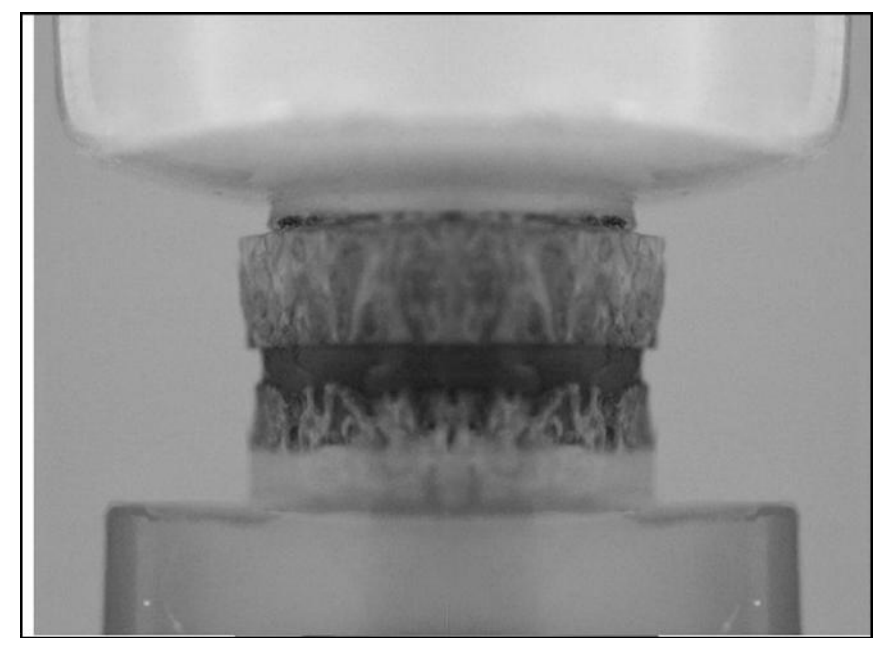

Fig. (2). Construct with BMDSCs in a fibrin matrix.

RNA isolation was started within two minutes. Under sterile conditions the fibrin-DMEM matrices were harvested from the compression bioreactors: the matrix was dissected sharply from the cancellous bone and transferred immediately into $2 \mathrm{ml}$ RNA-extraction solution (Trifast, Peqlab, Germany). Matrices were homogenized mechanically 
(Ultra-Turrax-T8, IKA, Germany) directly afterwards. The RNA extraction was performed according to the protocol of the supplier. RNA integrity was controlled in a Bio Sizing Assay (Eukaryote Total RNA Nano, Agilent Technologies 2100 Bioanalyzer, Germany). After measurement of total RNA using a photometer, the RNA was stored at $-140^{\circ} \mathrm{C}$ until further use.

The expression of osteogenesis-specific genes was investigated using the GEArray-Q-Series Human Osteogenesis

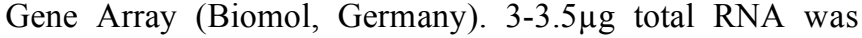
used for each array. cDNA synthesis was accomplished at $37^{\circ} \mathrm{C}$ for 25 minutes. The subsequent labelling was carried out with Biotin-16-dUTP (Roche, Germany) and an amplification labelling kit (Biomol, Germany) according to the protocol of the supplier. 30 cycles of PCR amplification were implemented, with $85^{\circ} \mathrm{C}, 50^{\circ} \mathrm{C}$ and $72^{\circ} \mathrm{C}$ for 1 minute each (MJ Research Inc, USA). Hybridisation of the PCR product on the arrays was carried out at $56^{\circ} \mathrm{C}$ for 12 hours. Unspecific binding had been blocked by prehybridisation with salmon-sperm DNA (Roche Diagnostics, Germany) for 2 hours. After labelling with streptavidin-biotin antibodies and addition of CDP-Star solution (Biomol, Germany), the array signal was transmitted onto x-ray films (Kodak, Germany). Films were developed and scanned. The gene expression was analyzed using the programs ScanAlyze Version 2.5 (Eisen Software, USA) and GEArray Analyzer 1.3 (Superarray, USA). Following the recommendation of the array supplier, genes with unreliably low signals were excluded from further analysis.

\section{STATISTICS}

Statistical analysis was performed using SPSS 12.0. After background subtraction, the signals were normalized to the GAPDH as house keeping gene. The evaluation was carried out comparing directly the expression of mechanical stimulated cells versus controls of one donor. The expressions of the controls were defined as 1. All experiments were done in triplicate for all the 7 patients, all samples were subjected to DNA array analysis. A Wilcoxon signed rank test was carried out for statistical testing, a level of significance of $\mathrm{p}=0.05$ was chosen.

\section{RESULTS}

The RNA isolation was successful in all cases; all specimens could be included in the data analysis (Table 1). We noted a strong expression of core-binding-factor-1 (Cbfa1) in all BMSCs, showing no significant difference between the two treatment groups $(p=0,463)$. We found significant differen-ces in the expression of mechanically stimulated BMSCs compared to controls, as shown in Fig. (3).

\section{Matrix Proteins}

A significant difference was noted for the expression of the osteopontin (OPN) gene, which showed a 2.6-fold expression in mechanically stimulated cells, compared to controls $(\mathrm{p}=0.043)$.

\section{Cell-Surface Receptors}

Furthermore, we found a 2.6-fold increase in the expression of the integrin- $\beta$ - 1 gene and a 2.2 -fold increase in the expression of the transforming-growth-factor-betareceptor 1 (TGF- $\beta-\mathrm{R} 1)$, both differences being significant $(\mathrm{p}=0.018)$.

\section{Intracellular Signalling Molecule}

The mechanical stimulation also had a direct effect on the expression of an intracellular signal molecule, the SMAD-5 gene, which showed a 2.4-fold increase $(\mathrm{p}=0.028)$.

Moreover, we found significant increases of two other genes: 1.8-fold for platelet-derived growth factor-alpha $(\mathrm{PDGF}-\alpha)(\mathrm{p}=0.027)$ and 1.6-fold for annexin-V $(\mathrm{p}=0.034)$.

\section{DISCUSSION}

BMSCs show high proliferative capacity and do not undergo terminal osteoblast differentiation in vitro without

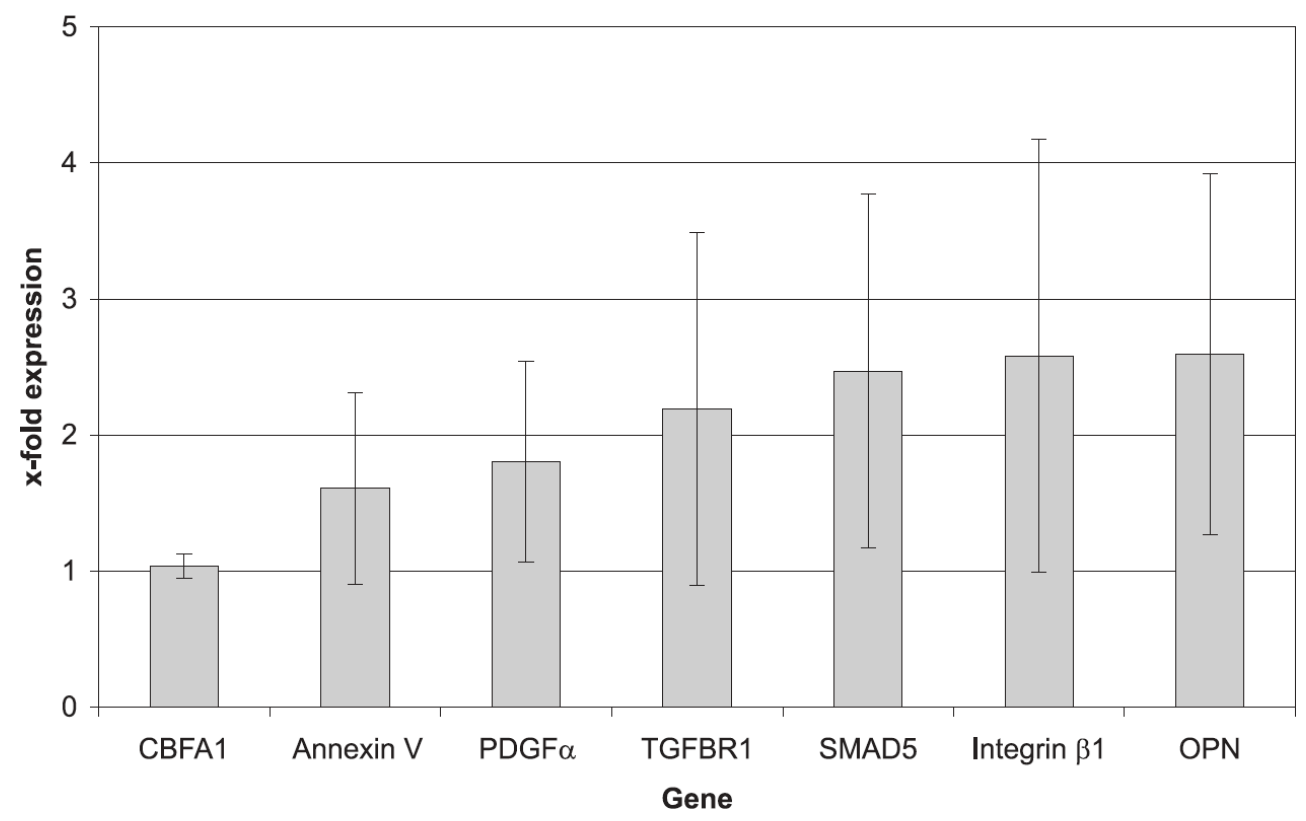

Fig. (3). Gene expression of mechanically loaded constructs normalized vs control constructs without mechanical stimulation. 
Table 1 Mean Changes in mRNA Expression of BMDSCs Through 24h of Mechanical Stimulation Normalized Versus Control Group w/o Mechanical Stimulation Measured with a Human Osteogenesis Gene Array (Biomol, Germany)

\begin{tabular}{|c|c|c|c|c|c|}
\hline Gene & Xfold Increase & Gene & Xfold Increase & Gene & Xfold Increase \\
\hline alk. phosphatase & 0 & COL7A1 & 0 & SMAD9 & 1.5 \\
\hline ARSE & 0 & GM-CSF & 0 & collagenase-3 & 0.9 \\
\hline Osteocalcin & 0 & G-CSF & 0.3 & gelatinase A & 0.9 \\
\hline BMP1 & 0 & Decorin & 1 & gelatinase B & 1 \\
\hline BMP2 & 0 & EGF & 0 & Hox 7 & 0.6 \\
\hline BMP3 & 0.1 & EGFR & 1.1 & MSX2 & 0 \\
\hline BMP 4 & 0 & FGF1 & 0.1 & NFkB & 0.4 \\
\hline BMP 8 & 0.6 & FGFR2 & 0 & CBP2 & 0.1 \\
\hline ALK-3 & 0.6 & FGFR3 & 0.2 & SOX9 & 0 \\
\hline CASR & 0.1 & FLT1 & 0 & SPARC cleav. prod. & 1.1 \\
\hline CD36 & 0.5 & fibronectin-1 & 0.8 & OPN & 2.6 \\
\hline CD36L1 & 1.3 & BMP3B & 0 & TGFb1 & 0 \\
\hline CD36L2 & -0.1 & ICAM-1 & 0 & TGF b2 & 0 \\
\hline COL10A1 & 0.3 & IGF-1 & 0.9 & TGF b3 & 1.4 \\
\hline COL11A1 & 1.7 & IGF-1R & 0 & TGFBR1 & 2.2 \\
\hline Endostatin & 0.6 & Integrin aV & 0.3 & VEGF & 0 \\
\hline COL19A1 & 0 & Integrin b1 & 2.6 & VEGF-B & 1.3 \\
\hline COL1A1 & 0 & SMAD1 & 0.9 & VEGF-C & 1.3 \\
\hline COL2A1 & 1.1 & SMAD2 & 1.1 & pUC18 & 0.1 \\
\hline COL3A1 & 1.4 & SMAD3 & 1.3 & 0 & 0 \\
\hline COL4A3 & 0 & DPC4/SMAD4 & 0.4 & GAPDH & 1 \\
\hline COL4A4 & 0 & SMAD5 & 2.4 & cyclophilin A & 2.3 \\
\hline COL4A5 & 0 & SMAD6 & 0 & RPL13A & 0.9 \\
\hline COL5A1 & 1.1 & SMAD7 & 0.8 & b-actin & 0.6 \\
\hline
\end{tabular}

external stimulation. In the present study, we could show for the first time that 24 hours of cyclic compression is able to increase the expression of several osteogenesis-specific genes and thereby lead to an osteogenic predifferentiation of BMSCs.

The gene expression analysis showed a marked expression of $\mathrm{Cbfa1}$, the master control gene of osteoblastic differentiation [23]. The BMSCs shifted to the level of immature osteoprogenitors [24].

By definition, these cells do not yet show expression of the typical markers for osteogenesis, like osteocalcin, alkaline phosphatase or type-I collagen, which were not detectable in our trial. However, they do express the noncollagenous matrix protein osteopontin [25], which was significantly increased by mechanical stimulation in our 
setting. It might be hypothesized that more BMSCs were directed towards immature osteoprogenitors.

As a non-collagenous protein of the bone matrix, OPN has further influences on bone metabolism: amongst others, it plays an important role during bone remodelling, inflammation and under mechanical stress $[25,26]$. An elevated OPN expression has also been noted during the early phase of fracture healing, prior to callus formation. As Kawahata and co-worker hypothesized that it might be a trigger for osteogenesis [27], the increased expression of OPN after 24 hours of cyclic compression may be an indicator of initial osteogenesis.

Another important effect of OPN has been identified in mice: ectopically implanted autologous bone showed lower transplant vascularization and integration, due to reduced bone remodelling [28]. A 2.6-fold increase of OPN expression by mechanical stimulation of constructs with BMSCs might thus augment bone remodelling and improve transplant vascularization and integration.

The mechanically stimulated BMSCs also showed an increased expression of integrin- $\beta 1$, a part of transmembrane glycoprotein that forms heterodimers with integrin- $\alpha$ subunits and links the cytoskeleton to the extracellular matrix. The importance of integrin- $\beta 1$ in osteogenesis and osteoblast function has been shown in mice [29]. Together with the $\alpha 1-3$ subunits, it binds to collagen, and ligandbinding leads to increased expression of osteoblast markers $[30,31]$. The $\beta 1$-subunit has been identified as the most important integrin in the development of BMSCs to osetoblasts [32]. Its increased expression might signalize the promotion of osteogenic differentiation in BMSCs following 24 hours of mechanical stimulation.

In addition, the mechanically stimulated BMSCs showed a significant increase in the expression of the TGF- $\beta$ receptor1 [33]. This receptor has been identified on osteoprogenitor cells and also on terminally differentiated osteoblasts [34]. Its ligand TGF- $\beta$ has been shown to be involved in the regulation of proliferation and migration of progenitor cells and leads to an increase of osteoblastic differentiation, independently of their differentiation state [35]. It promotes osteogenic differentiation in BMSCs, with enhanced matrix synthesis and calcification [36, 37]. The mechanically stimulated BMSCs with an increased expression of the TGF- $\beta$-receptor1 might therefore be more sensitive to TGF- $\beta$ stimuli and show augmented osteogenic differentiation when implanted into bone defects.

The increase of the intracellular signal molecule Smad-5 may be another indicator of osteogenic predifferentiation. Smad-5 interacts with Smad-1 and mediates signals from cytokines of the TGF- $\beta$ superfamily, and among them the osteoblastic differentiation of progenitor cells $[38,39]$. This may result in a facilitation of osteogenic differentiation of mechanically stimulated cells in bone defects.

The expression of the growth factor PDGF- $\alpha$ also increased following mechanical stimulation. PDGF- $\alpha$ is known to induce osteogenic differentiation, has additional chemotactic effects on osteoprogenitor cells and enhances the proliferation of osteoblasts [40]. These are all effects that may contribute to improved results following mechanical stimulation of BMSCs before using them in cell-based therapies.

Annexin- $\mathrm{V}$ gene expression was significantly increased after mechanical stimulation. Annexin- $\mathrm{V}$ protein builds $\mathrm{Ca}^{2+}$ channels, leading to mineralization of bone matrix in the growth plates during osteogenesis [41]. An increased expression of annexin- $\mathrm{V}$ enhances these processes of mineralization [42]. Such mineralization processes were observed in a prior study, whereas periosteal cells underwent long-term mechanical stimulation in bioreactors [20].

\section{CONCLUSION}

In recent years, different methods have been developed to stimulate osteogenic differentiation of BMSCs in vitro an in vivo, like medium supplements, growth factors or viral transfection $[1,43]$. The approach of mechanical stimulation presented here is advantageous, because it can be directly transferred to clinical application. The selected fibrin matrix allows temporary fixation of BMSCs in a bone defect and has shown excellent biocompatibility $[8,44]$.

Our results show a concomitant increase of genes coding for matrix molecules, receptors and growth factors by mechanical stimulation. The presented data indicate that 24 hours are sufficient to obtain changes in gene expression, resulting in an osteogenic predifferentiation of BMSCs. The shift towards immature osteoprogenitor cells combines the desired high proliferative capacity with an osteogenic potential that makes them a promising tool in cell-based treatment of bone defects. It may be postulated that shortterm mechanical stimulation will result in an improved osseous integration of tissue engineered grafts in bone defect healing.

\section{REFERENCES}

[1] Salgado AJ, Coutinho OP, Reis RL. Bone tissue engineering: state of the art and future trends. Macromol Biosci 2004; 4: 743-65.

[2] Yan MN, Dai KR, Tang TT, Zhu ZA, Lou JR. Reconstruction of peri-implant bone defects using impacted bone allograft and BMP2-gene-modified bone marrow stromal cells. J Biomed Mater Res A 2010; 933(1): 304-13.

[3] Brown KL, Cruess RL. Bone and cartilage transplantation in orthopaedic surgery. A review. J Bone Joint Surg Am 1982; 64: 270-9.

[4] Hooten JP Jr., Engh CA, Heekin RD, Vinh TN. Structural bulk allografts in acetabular reconstruction. Analysis of two grafts retrieved at post-mortem. J Bone Joint Surg Br 1996; 78: 270-5.

[5] Kwong LM, Jasty M, Harris WH. High failure rate of bulk femoral head allografts in total hip acetabular reconstructions at 10 years. $\mathrm{J}$ Arthroplasty 1993; 8: 341-6.

[6] Rose LJ. Autologous bone marrow transplants. Health Aff 2002; 21: 308 .

[7] Younger EM, Chapman MW. Morbidity at bone graft donor sites. J Orthop Trauma 1989; 3: 192-5.

[8] Perka C, Arnold U, Spitzer RS, Lindenhayn K. The use of fibrin beads for tissue engineering and subsequential transplantation. Tissue Eng 2001; 7: 359-61.

[9] Spitzer RS, Perka C, Lindenhayn K, Zippel H. Matrix engineering for osteogenic differentiation of rabbit periosteal cells using alphatricalcium phosphate particles in a three-dimensional fibrin culture. J Biomed Mater Res 2002; 59: 690-6.

[10] Quarto R, Mastrogiacomo M, Cancedda R, et al. Repair of large bone defects with the use of autologous bone marrow stromal cells N Engl J Med 2001; 344: 385-6.

[11] Bruder SP, Kraus KH, Goldberg VM, Kadiyala S. The effect of implants loaded with autologous mesenchymal stem cells on the healing of canine segmental bone defects. J Bone Joint Surg Am 1998; 80: 985-96. 
[12] Kon E, Muraglia A, Corsi A, et al. Autologous bone marrow stromal cells loaded onto porous hydroxyapatite ceramic accelerate bone repair in critical-size defects of sheep long bones. J Biomed Mater Res 2000; 49: 328-37.

[13] Braccini A, Wendt D, Farhadi J, Schaeren S, Heberer M, Martin I. The osteoenicity of implanted engineered bone constructs is related to the density of clonogenic bone marrow stromal cells. J Tissue Eng Regen Med 2007; 1: 60-5.

[14] Prockop, DJ. Marrow stromal cells as stem cells for nonhematopoietic tissues. Science 1997; 276: 71-4.

[15] Banfi A, Bianchi G, Notaro R, Luzzatto L, Cancedda R, Quarto, R. Replicative aging and gene expression in long-term cultures of human bone marrow stromal cells. Tissue Eng 2002; 8: 901-10.

[16] Derubeis, AR, Cancedda R. Bone marrow stromal cells (BMSCs) in bone engineering: limitations and recent advances. Ann Biomed Eng 2004; 32: 160-5.

[17] Cancedda R, Mastrogiacomo M, Bianchi G, Derubeis A, Muraglia A, Quarto R. Bone marrow stromal cells and their use in regenerating bone. Novartis Found Symp 2003; 249: 133-43.

[18] Ng AM, Saim AB, Tan KK, et al. Comparison of bioengineered human bone construct from four sources of osteogenic cells. J Orthop Sci 2005; 10: 192-9.

[19] Mauney JR, Sjostorm S, Blumberg J, et al. Mechanical stimulation promotes osteogenic differentiation of human bone marrow stromal cells on 3-D partially demineralized bone scaffolds in vitro. Calcif Tissue Int 2004; 74: 458-68.

[20] Matziolis G, Tuischer J, Kasper G, et al. Simulation of cell differentiation in fracture healing-mechanically loaded composite scaffolds in a novel bioreactor system. Tissue Eng 2006; 12: 201-8.

[21] Paul JP, McGrouther DA. Forces transmitted at the hip and knee joint of normal and disabled persons during a range of activities. Acta Orthop Belg 1975; 41 Suppl 1: 78-88.

[22] Krishnan R, Mariner EN, Ateshian GA. Effect of dynamic loading on the frictional response of bovine articular cartilage. J Biomech 2005; 38: 1665-73.

[23] Schinke T, Karsenty G. Transcriptional control of osteoblast differentiation and function. In: Bilezikan JP, Raisz LG, Rodan GA, Eds. Principles of Bone Biology. $2^{\text {nd }}$ ed, San Diego: Academic Press 2001; pp. 83-91.

[24] Aubin JE, Triffit JT. Mesenchymal stem cells and osteoblast differentiation. In: Bilezikan, JP, Raisz LG, Rodan GA, Eds. Principles of Bone Biology. $2^{\text {nd }}$ ed, San Diego: Academic Press 2001; pp. 59-81.

[25] Mark MP, Prince CW, Gay S, et al. A comparative immunocytochemical study on the subcellular distributions of $44 \mathrm{kDa}$ bone phosphoprotein and bone gamma-carboxyglutamic acid (Gla)containing protein in osteoblasts. J Bone Miner Res 1987; 2: 337 46.

[26] Noda M, Denhardt DT. Osteopontin. In: Bilezikan, JP, Raisz LG, Rodan GA, Eds. Principles of Bone Biology. $2^{\text {nd }}$ ed. San Diego: Academic Press 2001; pp. 239-50.

[27] Kawahata H, Kikkawa T, Higashibata Y, et al. Enhanced expression of Runx2/PEBP2alphaA/CBFA1/AML3 during fracture healing. J Orthop Sci 2003; 8: 102-8.
[28] Asou Y, Rittling SR, Yoshitake, H, et al. Osteopontin facilitates angiogenesis, accumulation of osteoclasts, and resorption in ectopic bone. Endocrinology 2001; 142: 1325-32.

[29] Zimmerman D, Jin F, Leboy P, Hardy S, Damsky C. Impaired bone formation in transgenic mice resulting from altered integrin function in osteoblasts. Dev Biol 2000; 220: 2-15.

[30] Horton MA. Integrin antagonists as inhibitors of bone resorption: implications for treatment. Proc Nutr Soc 2001; 60: 275-81.

[31] Xiao G, Wang D, Benson MD, Karsenty G, Franceschi RT. Role of the alpha2-integrin in osteoblast-specific gene expression and activation of the Osf2 transcription factor. J Biol Chem 1998; 273: 32988-94.

[32] Gronthos S, Simmons PJ, Graves SE, Robey PG. Integrin-mediated interactions between human bone marrow stromal precursor cells and the extracellular matrix. Bone 2001; 28: 174-81.

[33] Huang CY, Reuben PM, Cheung HS. Temporal expression patterns and corresponding protein inductions of early responsive genes in rabbit bone marrow-derived mesnchymal stem cells under cyclic compressive loading. Stem Cells 2005; 23: 1113-21.

[34] Chang DJ, Ji C, Kim KK, Casinghino S, McCarthy TL, Centrella M. Reduction in transforming growth factor beta receptor I expression and transcription factor $\mathrm{CBFa} 1$ on bone cells by glucocorticoid. J Biol Chem 1998; 273: 4892-6.

[35] Kassem M, Kveiborg M, Eriksen EF. Production and action of transforming growth factor-beta in human osteoblast cultures: dependence on cell differentiation and modulation by calcitriol. Eur J Clin Invest 2000; 30: 429-37.

[36] Lieb E, Milz S, Vogel, T, Hacker M, Dauner M, Schulz MB. Effects of transforming growth factor betal on bonelike tissue formation in three-dimensional cell culture. I. Culture conditions and tissue formation. Tissue Eng 2004; 10:1399-413.

[37] Lieb E, Vogel T, Milz S, Dauner M, Schulz MB. Effects of transforming growth factor beta1 on bonelike tissue formation in three-dimensional cell culture. II: Osteoblastic differentiation. Tissue Eng 2004; 10: 1414-25.

[38] Nishimura R, Kato Y, Chen D, Harris SE, Mundy GR, Yoneda T. Smad5 and DPC4 are key molecules in mediating BMP-2-induced osteoblastic differentiation of the pluripotent mesenchymal precursor cell line C2C12. J Biol Chem 1998; 273: 1872-9.

[39] Erlebacher A, Filvaroff EH, Ye JQ, Derynck R. Osteoblastic responses to TGF-beta during bone remodeling. Mol Biol Cell 1998; 9: 1903-18.

[40] Fiedler J, Etzel N, Brenner RE. To go or not to go: Migration of human mesenchymal progenitor cells stimulated by isoforms of PDGF. J Cell Biochem 2004; 93: 990-8.

[41] Plate U, Tkotz T, Wiesmann HP, Stratmann U, Joos U, Hohling HJ. Early mineralization of matrix vesicles in the epiphyseal growth plate. J Microsc 1996; 183: 102-7.

[42] Wang W, Xu J, Kirsch T. Annexin V and terminal differentiation of growth plate chondrocytes. Exp Cell Res 2005; 305: 156-65.

[43] Gazit D, Turgeman G, Kelley P, et al. Engineered pluripotent mesenchymal cells integrate and differentiate in regenerating bone: a novel cell-mediated gene therapy. J Gene Med 1999; 1: 121-33.

[44] Arnold U, Schweitzer S, Lindenhayn K, Perka C. Optimization of bone engineering by means of growth factors in a threedimensional matrix. J. Biomed Mater Res A 2003; 67: 260-9.

(C) Matziolis et al.; Licensee Bentham Open.

This is an open access article licensed under the terms of the Creative Commons Attribution Non-Commercial License (http://creativecommons.org/licenses/by$\mathrm{nc} / 3.0 /$ ) which permits unrestricted, non-commercial use, distribution and reproduction in any medium, provided the work is properly cited. 